\title{
Acid secretion and sensitivity to gastrin in patients with duodenal ulcer: effect of eradication of Helicobacter pylori
}

\author{
Steven F Moss, John Calam
}

\begin{abstract}
The effect of ulcer healing with eradication of Helicobacter pylori ( $H$ pylori) on gastric function was investigated in nine patients with duodenal ulcer disease. One month after eradication there were significant reductions in both basal plasma gastrin concentration, from a median (range) of $19(1-22)$ to $6(2-15) \mathrm{pmol} / \mathrm{l}$ $(\mathrm{p}<0.05)$, and of basal acid secretion from 8.3 $(2.4-24)$ to $2.6(1 \cdot 4-8 \cdot 1) \mathrm{mM} \mathrm{H}^{+} / \mathrm{h},(\mathrm{p}<0.01)$. The peak acid secretion rate was unchanged from 37 (16-59) to 37 (21-59) $\mathrm{mM} \mathrm{H}^{+} / \mathrm{h}$. After treatment there was no change in the parietal cell sensitivity to stepped infusions of gastrin heptadecapeptide: the median concentration of gastrin required for $50 \%$ of maximal acid secretion $\left(E_{50}\right)$ was $41(14 \cdot 8-126)$ before and 33 (23-125) $\mathrm{pmol} / \mathrm{l}$ after eradication of $H$ pylori. The metabolic clearance rate of gastrin was also unaffected by the eradication of $\boldsymbol{H}$ pylori. Thus eradication of $\boldsymbol{H}$ pylori infection from patients with active duodenal ulcers is accompanied by falls in both basal gastrin release and basal acid secretion without a change in the parietal cell sensitivity to gastrin. Cyclical changes in $\boldsymbol{H}$ pylori infection may cause the variations in basal acid secretion that are seen in duodenal ulcer disease.

(Gut 1993; 34: 888-892)
\end{abstract}

Despite the strong epidemiological and clinical evidence implicating the bacterium Helicobacter pylori ( $H$ pylori) in the pathogenesis of chronic duodenal ulcer disease, ${ }^{1}$ the way that the organism promotes recurrence of ulcers remains unclear.

The discovery that $H$ pylori increases plasma gastrin concentrations raised the possibility that $H$ pylori may be responsible for the known abnormalities of gastric acid secretion that have been described in patients with duodenal ulcers. These include high basal and peak acid outputs, a high ratio of basal to peak acid secretion, increased meal stimulated acid output, and impairment of the normal inhibition of gastrin release and acid secretion by luminal acid. ${ }^{2-5}$

Helicobacter pylori increases plasma gastrin concentrations by $50 \%$ to $100 \%$ and values fall to normal after the organism has been eradicated..$^{6-10}$ Despite this reduction in plasma gastrin, no consistent changes in rates of acid secretion have been documented after eradication treatment. This has led to the suggestion that $H$ pylori infection might decrease the sensitivity of parietal cells to gastrin, ${ }^{11}$ but other evidence did not support this view. Chittajallu et al were unable to detect a change in the response to stepped infusions of pentagastrin on eradication of $H$ pylori from patients with duodenal ulcer disease, although circulating concentrations of pentagastrin were not measured. ${ }^{12}$ Furthermore, earlier studies of patients with duodenal ulcer disease, who were presumably mostly infected, showed their parietal cells to be, if anything more sensitive to gastrin than those of controls, ${ }^{1314}$ although it was not known whether the controls were infected with $H$ pylori.

We therefore studied acid secretory responses to gastrin in a series of patients with duodenal ulcer disease before and after treatment to eradicate $H$ pylori. Because the hypergastrinaemia in $H$ pylori infection is predominantly due to an increase in the antral gastrin form, gastrin heptadecapeptide (G17), ${ }^{15}{ }^{16}$ we infused G17 intravenously and determined the effect of eradication of $H$ pylori on acid secretion, parietal cell sensitivity to gastrin, and the metabolic clearance of $\mathrm{G} 17$.

\section{Methods}

\section{PATIENTS AND TREATMENT}

The study was approved by the local ethics committee. Eleven patients were recruited from our outpatient clinic and informed consent was obtained. The patients, eight men, had a median age of 34 (range 21-76) years; five were smokers, each smoking 20 cigarettes per day. As entry criteria they all had active uncomplicated duodenal ulceration at endoscopy and $H$ pylori infection diagnosed by a biopsy urease test, histology, and bacterial culture. At least two of these tests were positive in all the patients studied at entry. None had any complicating medical condition or previous history of gastric surgery, or had taken antibiotics or bismuth preparations in the previous six months. Apart from antacids none of the patients had taken any medical treatment during the 14 days before their initial endoscopy.

Acid secretory responses to gastrin (see later) were measured within five days of endoscopy. Patients were then treated with $120 \mathrm{mg}$ tripotassium dicitratobismuthate (DeNol, Brocades, Weybridge, Surrey, UK) four times daily for one month, $400 \mathrm{mg}$ metronidazole three times daily, and $500 \mathrm{mg}$ tetracycline four times daily taken concurrently for the first two weeks of treatment. Four weeks after the end of treatment endoscopy was repeated and biopsies were taken. The acid secretory tests were repeated within five days of the second endoscopy. 


\section{G17 DOSE-RESPONSE STUDIES}

Patients attended the clinical investigation unit at 9.00 am after fasting overnight. Indwelling venous cannulae were inserted into the right forearm for infusion of $\mathrm{Gl} 7$ and into the left forearm for blood sampling. Gastric acid secretion was measured by aspiration as described by Baron. ${ }^{3}$ Briefly, a nasogastric tube was passed, resting juice was aspirated, and the position of the tube was checked by water recovery. The tube used was a multifenestrated sump tube with a second channel for infusing phenol red into the proximal stomach and a third lumen for equilibration of intragastic and atmospheric pressure. The patient remained semirecumbent throughout. Gastric contents were constantly aspirated under $20 \mathrm{~mm} \mathrm{Hg}$ negative pressure (Air Shields, Hatboro, $\mathrm{Pa}, \mathrm{USA}$ ) and the patency of the tube was ensured by the manual insufflation of $20 \mathrm{ml}$ air every five minutes.

The G17 (Gastrin I Human; Sigma, Poole, Dorset, UK) made up in $0 \cdot 15 \mathrm{M}$ saline containing $1 \%$ albumin was infused continuously by an infusion pump (Vickers Medical, Basingstoke, Hants, UK) at doses of $0,11,33,100$, and 300 $\mathrm{pmol} / \mathrm{kg} / \mathrm{h}$, each for a 30 minute period. The largest dose produces maximal stimulation of acid secretion. ${ }^{14}{ }^{17}$ Gastric acid was collected continuously on to ice and the acid output during each 15 minute period was measured by titration to $\mathrm{pH} 7$ with $0 \cdot 1 \mathrm{M} \mathrm{NaOH}$. The rate of acid secretion was calculated with correction for pyloric losses and duodenogastric reflux by phenol red recovery and sodium measurement respectively. ${ }^{3}$ Median (range) gastric juice recoveries were $90(74-100) \%$ before and $85(78$ $100) \%$ after treatment. Basal acid output per hour was calculated by doubling the acid output during the $\mathbf{3 0}$ minutes of infusion of saline only. Other acid outputs were calculated by multiplying the acid output during the second 15 minutes of each infusion period by four. Blood samples were taken at the end of each infusion period for gastrin assay.

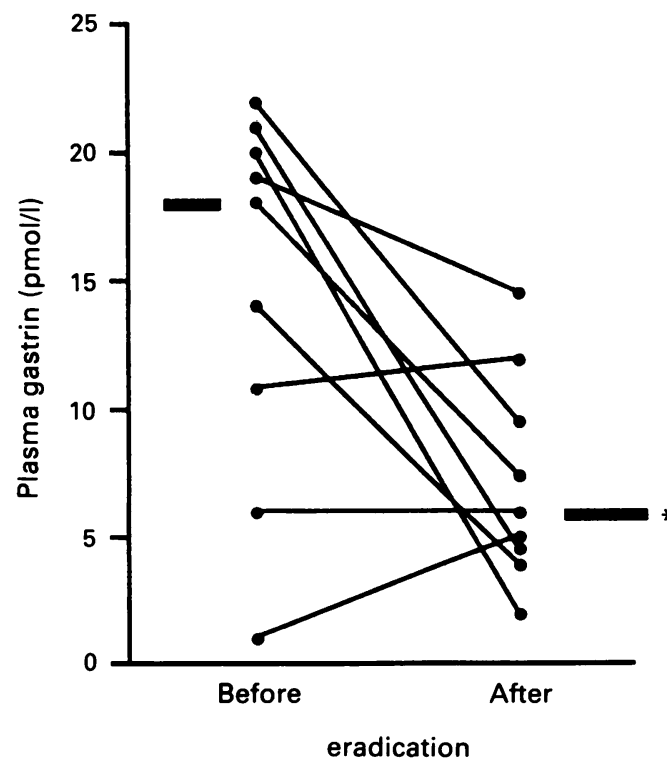

Figure 1: Changes in basal plasma gastrin concentration in nine patients with duodenal ulcers after eradication of

$\mathbf{H}$ pylori with tripotassium dicitratobismuthate, tetracycline, and metronidazole. Bars represent median values. ${ }^{\star} p<0.05$.

\section{MEASUREMENT OF GASTRIN}

Blood was collected into chilled tubes containing EDTA and the plasma was separated promptly and frozen at $-20^{\circ} \mathrm{C}$. Plasma gastrin concentration was measured by radioimmunoassay with antibody G179 provided by Professor Bloom. ${ }^{18}$ All samples were assayed in duplicate and in the same assay. Individual dose-response curves were then plotted.

\section{STATISTICAL ANALYSIS}

The data were analysed with an Arcus 2 statistical package (Medical Computing, Aughton, W. Lancs, UK). Wilcoxon's rank sum test was used to compare differences before and after treatment and the results are expressed as medians (ranges) and 95\% confidence intervals (95\% CIs). A p value $<0.05$ was considered to signify statistical significance.

\section{Results}

\section{CLINICAL}

At repeat endoscopy ulcers had healed in 10 of the 11 patients. The patient with a duodenal ulcer at the end of treatment (man aged 31 years) had positive urease, histology, and bacteriology for $H$ pylori when retested and a woman aged 66 years still had a positive urease test after treatment. These patients were excluded from further analysis. In the remaining nine patients $H$ pylori was successfully eradicated, and endoscopic findings were normal. Data from these nine patients were then analysed further.

\section{BASAL PLASMA GASTRIN}

Basal plasma gastrin concentrations fell significantly after the eradication of $H$ pylori (Fig 1 ). The median basal plasma gastrin concentration before treatment was 19 (range $1-22,95 \% \mathrm{CI}$ 9-20) pmol/l compared with 6 (2-15, 95\% CI 4-11) pmol/l after $(\mathrm{p}<0.05)$.

BASAL AND PEAK ACID SECRETION RATES

Figure 2 shows that after eradication of $H$ pylori there was a reduction of basal acid output in eight patients and no change in one patient. The median basal acid output fell significantly from $8 \cdot 3(2 \cdot 4-24,95 \% \mathrm{CI} 4 \cdot 4-16)$ to $2 \cdot 6(1 \cdot 4-8 \cdot 1,95 \%$ CI 2.0-6.0) $\mathrm{mM} \mathrm{H}^{+} /$hour $(\mathrm{p}<0 \cdot 01)$. The peak acid output was unchanged, from 37 (16-59, $95 \%$ CI 31-45) to $37(21-59,95 \%$ CI $27-45) \mathrm{mM}$ $\mathrm{H}^{+}$/hour after treatment.

\section{PARIETAL CELL SENSITIVITY TO GASTRIN}

Figure 3 shows that for the nine patients as a group, there was a linear relation between the mean plasma gastrin during infusion of G17 plotted on a log scale and the mean acid output at each of the G17 doses. This relation was linear both before and after treatment, with correlation coefficients of $0.99(p<0.001,95 \%$ CI $0.89-1.00)$ and $0.98(\mathrm{p}<0.005,95 \% \mathrm{CI} 0.71-1.00)$ respectively. The only differences between the two lines is that after treatment there was a lower mean 


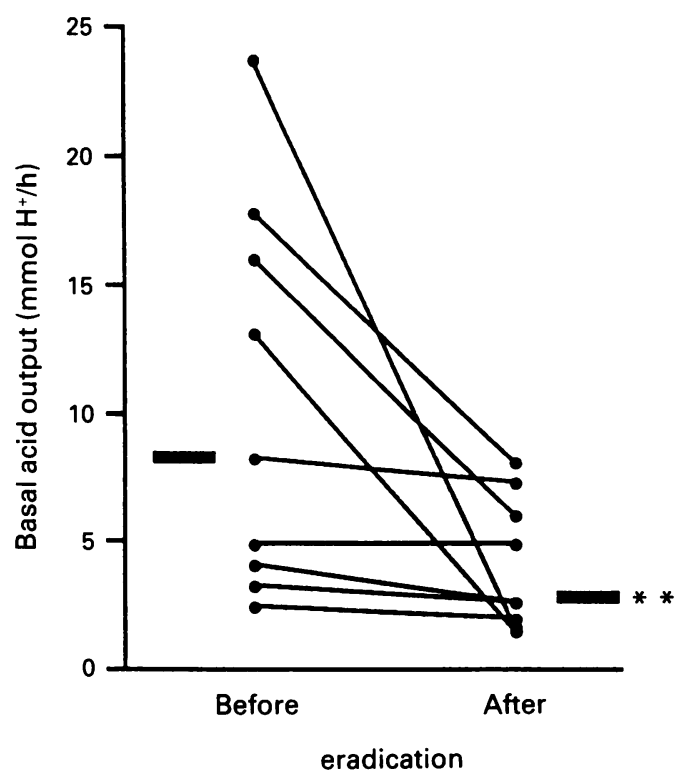

Figure 2: Basal acid output before and after eradication of $\mathrm{H}$ pylori. Bars represent median values. ${ }^{\star \star} p<0.01$.

plasma gastrin concentration and a lower mean acid secretion rate under basal conditions. Consequently, the mean concentration of gastrin necessary to produce half maximal acid secretion $\left(\mathrm{EC}_{50}\right)$ was identical, both before and after eradication of $H$ pylori.

Individual dose-response curves for each patient were also plotted. From these the $\mathrm{EC}_{50}$ for each patient - rather than the group as a whole - was determined, both before and after eradication of $H$ pylori. In the nine patients in whom $H$ pylori was eradicated, the median correlation coefficient of the individual regression plot of log dose against response was 0.93 $(0.85-0.96)$ before and $0.94(0.89-0.99)$ after treatment. There was no significant difference in the $\mathrm{EC}_{50}$ after the eradication of $H$ pylori. The median $\mathrm{EC}_{50}$ was $41(14 \cdot 8-126) \mathrm{pmol} / \mathrm{l}$ before and $33(23-125) \mathrm{pmol} / \mathrm{l}$ after eradication.

The basal-subtracted $\mathrm{EC}_{50}$ - the concentration of gastrin necessary to increase acid secretion from basal to half maximal acid secretion - has been advocated by some workers to be a more appropriate index of parietal cell sensitivity. ${ }^{19}$ This is because this analysis excludes the effect of changes in basal acid secretion, which is thought to be independent of gastrin. ${ }^{2021} \mathrm{We}$ therefore also plotted individual dose-response curves of log plasma gastrin against the basalsubtracted acid output. The correlation coefficients for these plots were $0.94(0.85-0.96)$ and $0.94(0.88-0.99)$ before and after treatment respectively. In the nine patients in whom $H$ pylori was successfully eradicated the median basal-subtracted $\mathrm{EC}_{50}$ fell significantly, from 104 (18-171, 95\% CI 53-150) to 48 (26-136, 95\% CI 34-103) $\mathrm{pmol} / \mathrm{l}(\mathrm{p}<0.05)$.

\section{METABOLIC CLEARANCE RATES OF G17}

By comparing the infused G17 dose with the plasma gastrin response the metabolic clearance rate of G17 can be calculated by two different methods as described by Blair et al. ${ }^{22}$ The clearance rate can be calculated by the reciprocal

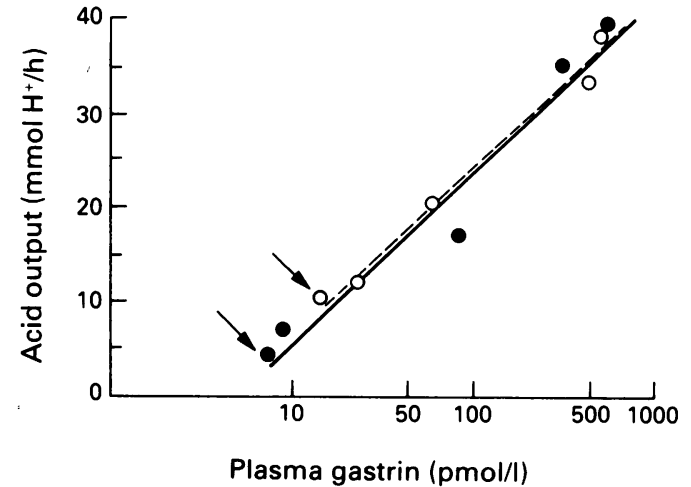

Figure 3: Relation between mean plasma gastrin concentration and acid output during the last 15 minute period of each $G 17$ infusion. Mean values for the nine patients at each dose of $\mathrm{Gl} 7$ before eradication of $\mathrm{H}$ pylori are indicated by open circles joined by the dashed line and after eradication by dark circles and bold line. The points indicated by arrows represent mean values under basal conditions.

of the slope of the regression line between G17 dose and plasma gastrin and by the plateau principle at an infusion rate of $\mathrm{G} 17$ of $300 \mathrm{pmol} /$ $\mathrm{kg} /$ hour. The metabolic clearance rate of $\mathrm{Gl}$ was $8(6-93)$ before and $8(6-76) \mathrm{ml} / \mathrm{kg}$. min after treatment when calculated by the first method and $9(6-74)$ and $8(6-62) \mathrm{ml} / \mathrm{kg}$. min respectively by the second method. Therefore the clearance of G17 was not altered by the eradication of H pylori.

\section{Discussion}

Our current results confirm that treatment which both heals duodenal ulcers and eradicates $H$ pylori significantly decreases basal plasma gastrin concentrations. We have also shown for the first time such treatment also decreases basal gastric acid secretion significantly. Thus $H$ pylori infection combined with active ulceration may cause the increased basal acid secretion seen in duodenal ulcer disease.

Several previous studies have shown that eradication of $H$ pylori, with or without ulcer healing, produces a fall in fasting plasma gastrin concentrations. ${ }^{6-10}$ Abolition of the exaggerated gastrin release is probably due to an increase in the synthesis of somatostatin in the antral mucosa. ${ }^{23-25}$ Despite a fall in the basal plasma gastrin concentration, however, it has not been shown previously that eradication of $H$ pylori can significantly decrease the basal acid output. Two previous studies, one by ourselves in patients with duodenal ulcers ${ }^{26}$ and another by Mountbriand $e t$ al in dyspeptic patients ${ }^{27}$ showed no significant change in basal acid output after anti- $H$ pylori treatment. In both studies the patients were retested within a week of ending treatment, however, so that in some cases infection may have persisted. ${ }^{28}$ When six patients with duodenal ulcers in whom $H$ pylori had been eradicated were retested after 12 months, we found that the median basal acid output fell by about $40 \%,{ }^{29}$ although the change was not significant. Fullarton et al noted a fall of about the same degree, one month after eradicating $H$ pylori from eight patients with inactive duodenal ulcer disease, but again the change was not statistically significant. ${ }^{30}$ We also found the basal acid output 
to be significantly greater in patients with duodenal ulcers and with $H$ pylori than in patients with duodenal ulcers without this infection. ${ }^{6} \mathrm{It}$ is difficult to deduce the physiological effect of $H$ pylori on basal secretion from this and other studies in which patients do not act as their own controls, because other differences between the groups might affect acid secretion. For example, $H$ pylori is implicated in the pathogenesis of atrophic gastritis, ${ }^{31}$ which may have led to decreased acid secretion through loss of parietal cells in groups of chronically infected subjects in some studies. ${ }^{32}$ The fall in basal acid secretion found may not necessarily be due to the eradication of $H$ pylori. Achord noted that the basal acid output decreased after healing of an ulcer by drugs that do not eradicate $H$ pylori ${ }^{33}$ implying that the ulcer crater is itself associated with increased basal acid secretion. Further studies will be necessary to determine which factor - the ulcer crater or $H$ pylori - is reponsible for the increased basal acid output.

Our present findings are consistent with the generally accepted view that peak acid output reflects the parietal cell mass and is not altered by eradication of $H$ pylori. ${ }^{10} 272930$ The main purpose of our present study was to determine whether chronic infection with $H$ pylori alters the sensitivity of the parietal cells to gastrin. This was suggested by the relative lack of change in rates of acid secretion and intragastric acidity on eradication of $H$ pylori despite substantial falls in circulating gastrin concentrations, ${ }^{6-10}$ and by the suppression of acid secretion produced by $H$ pylori on first infection. ${ }^{34}$

We measured circulating gastrin to determine the concentrations of gastrin required to produce half maximal acid secretion. There has been debate as to whether this should be calculated with or without subtraction of basal acid secretion. It is widely held that the increased basal acid secretion in patients with duodenal ulcer disease is determined by vagal drive rather than circulating gastrin..$^{221}$ This is the rationale for determining the basal subtracted $\mathrm{EC}_{50}$ in some previous studies. ${ }^{13141719}$ We found that basalsubtracted $\mathrm{EC}_{50}$ does fall significantly on eradication of $H$ pylori, suggesting that the infection initially present did indeed decrease the sensitivity of parietal cells to gastrin. The effect of eradication of $H$ pylori on basal gastrin and acid secretion is more consistent with the idea that circulating gastrin is responsible for driving basal acid secretion in patients with duodenal ulcer, because the fall in basal gastrin concentration on eradication was accompanied by a proportional fall in basal acid secretion. Therefore the $\mathrm{EC}_{50}$, rather than the derived basalsubtracted $\mathrm{EC}_{50}$, is likely to be the most appropriate measure of parietal cell sensitivity and the $\mathrm{EC}_{50}$ did not change after healing with eradication of $H$ pylori. It is now clear that the change in basal-subtracted $\mathrm{EC}_{50}$ on eradication plus healing is only a mathematical consequence of the fall in gastrin driven basal acid secretion. This is best appreciated when the mean acid output is plotted against mean plasma gastrin concentration for each G17 infusion (Fig 3); the two lines are identical when exogenous gastrin is infused. These graphs are similar to those obtained by
Hirschowitz et $a l^{17}$ and by Blair et $a l^{22}$ who compared G17 dose-response curves in patients with ulcers and control subjects, after normalising for differences in peak acid secretion rates; the only difference between the two groups of patients was under basal conditions.

Blair et al found that the metabolic clearance rate of G17 was lower in patients with duodenal ulcers than in controls. ${ }^{19}$ Our results show no change in the clearance of G17 on eradication of $H$ pylori. The results that we obtained were similar to the results in their duodenal ulcer group so that the results of Blair et al cannot be explained by the presence of $H$ pylori.

Our present results show that healing of duodenal ulcers with a regime that also eradicates $H$ pylori produces a fall in basal acid secretion that may be due to the concomitant fall in basal plasma gastrin concentration. Increased basal acid secretion has been implicated in duodenal ulcerogenesis and correction of this abnormality may contribute to the prolonged remissions of this disease seen after eradication of $H$ pylori.

We are grateful to Dr John $\mathrm{H}$ Walsh for his helpful advice, to Ash Waheed and Kang Li for expert technical assistance, and to the staff of the endoscopy unit for their cooperation. This work was stapf of the endoscopy unit for their cooperation. This work supported by a Wellcome Trust Research Fellowship Award.
Part of this study was presented at the autumn meeting of the British Society of Gastroenterology, September 1992.

1 Moss S, Calam J. Helicobacter pylori and peptic ulcers: the present position. Gut 1992; 33: 289-92.

2 Blair AJ, Feldman M, Barnett C, Walsh JH, Richardson CT. Detailed comparison of basal and food-stimulated gastric acid secretion rates and serum gastrin concentrations in duodenal ulcer patients and normal subjects. $\mathcal{F}$ Clin Invest 1987; 79: 582-7.

3 Baron JH. Clinical tests of gastric secretion. London: Macmillan Press, 1978.

4 Soll AH. Duodenal ulcer and drug therapy. In: Sleisenger MH, Fordran JS, eds. Gastointestinal disease. 4th ed. Philadelphia: WB Saunders, 1989.

5 Walsh JH, Richardson CT, Fordtran JS, $\mathrm{pH}$ dependence of acid secretion and gastrin release in normal and ulcer acid secretion and gastrin release in

6 Levi S, Beardshall K, Haddad G, Playford R, Ghosh P, Calam J. Campylobacter pylori and duodenal ulcer; The gastrin link. Lancet 1989; i: 1167-8.

7 McColl KE, Fullarton GM, El Nujumi AM, Macdonald AM, Brown IL, Hilditch TE. Lowered gastrin and gastric acidity after eradication of Campylobacter pylori in duodenal ulcer. Lancet 1989; ii: 499-500.

8 Smith JTL, Pounder RE, Nwokolo CU, Lanzon-Miller S, Evans DG, Graham DY, Evans DJ. Inappropriate hypergastrinaemia in asymptomatic healthy subjects infected with Helicobacter pylori. Gut 1990; 31: 522-5.

9 Graham DY, Opekun A, Lew GM, Evans DJ Jr, Klein PD, Evans DG. Ablation of exaggerated meal stimulated gastrin release in duodenal ulcer patients after clearance of Helicobacter (Campylobacter) pylori infection. Am $\mathcal{f}$ Gastroenterol bacter (Campylo

10 Levi S, Beardshall K, Swift I, Foulkes W, Playford R, Ghosh $\mathrm{P}$, Calam J. Antral Campylobacter pylori, hypergastrinaemia, and duodenal ulcers: Effect of eradicating the organism. BMF 1989; 299: 1504-5.

1 Blaser MJ. Hypotheses on the pathogenesis and natural history of Helicobacter pylori-induced inflammation. Gastroenterology 1992; 102: 720-7.

12 Chittajallu RS, Howie CA, McColl KEL. Effect of Helicobacter pylori on parietal cell sensitivity to pentagastrin in duodenal ulcer subjects. Scand fु Gastroenterol 1992; 27: 857-62.

13 Isenberg JI, Grossman MI, Maxwell V, Walsh JH. Increased sensitivity to stimulation of acid secretion by pentagastrin in duodenal ulcer. $\mathcal{F}$ Clin Invest 1975; 75: 330-7.

14 Lam SK, Isenberg JI, Grossman MI, Lane WH, Walsh JH. Gastric acid secretion is abnormally sensitive to exogenous Gastric acid secretion is abnormally sensitive to exogenous gastrin released after peptone test meal
patients. $\mathcal{F}$ Clin Invest $1980 ; 65: 55-62$.

15 Mulholland G, Ardill JES, Chittajallu RS, McColl KEL. $H$ pylori-related hypergastrinaemia is due to a selective $H$ pylori-related hypergastrinaemia is due to a selective
increase in the G17 antral-derived hormone [Abstract]. Gut increase in the G17 antras

16 Beardshall K, Moss S, Gill J, Levi S, Ghosh P, Playford RJ, Calam J. Suppression of Helicobacter pylori diminishes 
gastrin releasing peptide-stimulated gastrin release in patients with duodenal ulcer. Gut 1992; 33:601-3.

17 Hirschowitz BI, Tim LO, Helman CA Molina E. Bombesin and G-17 dose responses in duodenal ulcer and controls. Dig Dis Sci 1985; 30: 1092-103.

18 Bloom SR, Long RG. Radioimmunoassay of gut regulatory peptides. London: WB Saunders, 1982.

19 Hirschowitz BI. Apparent and intrinsic sensitivity to pentagastrin of acid and pepsin secretion in peptic ulcer. Gastroenterology 1983; 86: 843-50.

20 Kirkpatrick PM, Hirschowitz BI. Duodenal ulcer with unexplained marked basal acid hypersecretion. Gastroenterology 1980; 79: 4-10.

21 Feldman M, Richardson CT, Fordtran JS. Effect of sham feeding on gastric acid secretion in healthy subjects and feeding on gastric acid secretion in healthy subjects and

22 Blair AJ, Richardson CT, Vasko M, Walsh JH, Feldman M. Comparison of acid secretory responsiveness to gastrin heptadecapeptide and of gastrin heptadecapeptide pharmacokinetics in duodenal ulcer patients and normal subjects. f Clin Invest 1986; 78: 779-83.

23 Haruma K, Sumii K, Okamoto S, et al. Helicobacter pylori infection causes low antral somatostatin content: pathogenesis of inappropriate hypergastrinaemia [Abstract]. Gastroenterology 1992; 102: A80

24 Murthy UK, Linscheer R, Cho C. The hypergastrinaemia in Helicobacter pylori gastritis is due to a decrease in antral D cell density and D:G ratio [Abstract]. Gastroenterology 1992; 102: A130.

25 Moss SF, Legon S, Bishop AE, Polak JM, Calam J. Effect of Helicobacter pylori on gastric somatostatin in duodenal

26 Levi S, Beardshall K, Desa LA, Calam J. Campylobacter pylori, gastrin, acid secretion and duodenal ulcer. Lancet 1989; ii: 613.

27 Mountbriand JR, Appleman HD, Cotner EK, Nostrant TT, Elta GH. Treatment of Campylobacter pylori does not alter gastric acid secretion. Am f Gastroenterol 1989; 84: 1513-6.

28 Weil J, Bell GD, Jones PH, Gant P, Trowell JE, Harrison G 'Eradication' of Campylobacter pylori: are we being misled? Lancet 1988; ii: 1245.

29 Moss SF, Ayesu K, Calam J. Gastrin and gastric acid output 1 year after eradication of $H$ pylori in duodenal ulcer patients [abstract]. Regul Pept 1991; 35: 251 .

30 Fullarton GM Chittaiallu R, McColl KEL. Effect of eradication of $H$ pylori on acid secretion in duodenal ulcer patients tion of $H$ pylori on acid secretion in duoden

31 Negrini R, Lisato L, Zanella I, et al. Helicobacter pylor infection induces antibodies cross-reacting with human gastric mucosa. Gastroenterology 1991; 101: 437-45.

32 Goldschmiedt $M$, Barnett CC, Schwarz BE, Karnes WE Redfern JS, Feldman $M$. Effect of age on gastric acid secretion and serum gastrin concentrations in healthy men and women. Gastroenterology 1991; 101: 977-90.

33 Achord JL. Gastric pepsin and acid secretion in patients with acute and healed duodenal ulcer. Gastroenterology 1981; 81 : 15-8.

34 Graham DY, Alpert LC, Lacey-Smith J, Yoshimura HH. Iatrogenic Campylobacter infection is a cause of epidemic latrogenic Campylobacter infection is a cause of
achlorhydria. Am $\mathcal{F}$ Gastroenterol 1988; 83: 971-80. 